\title{
BMJ Open Clinical course and outcome of patients with COVID-19 in Mumbai City: an observational study
}

Rosemarie de Souza, ${ }^{1}$ Sharayu Mhatre, ${ }^{2}$ Burhanuddin Qayyumi, ${ }^{3}$ Garvit Chitkara, ${ }^{4}$ Tushar Madke, ${ }^{1}$ Mohan Joshi, ${ }^{1}$ Ramesh Bharmal, ${ }^{1}$ D S Asgaonkar, ${ }^{1}$ Prem Lakhani, ${ }^{1}$ Sudeep Gupta (D) , ${ }^{5,6}$ Pankaj Chaturvedi, ${ }^{3}$ Rajesh Dikshit (D) , ${ }^{7}$ Rajendra Badwe ${ }^{8}$

To cite: de Souza R, Mhatre S, Qayyumi B, et al. Clinical course and outcome of patients with COVID-19 in Mumbai City: an observational study. BMJ Open 2021;11:e042943. doi:10.1136/ bmjopen-2020-042943

- Prepublication history and additional supplemental material for this paper are available online. To view these files, please visit the journal online (http://dx.doi.org/10.1136/ bmjopen-2020-042943).

Received 27 July 2020 Revised 04 March 2021 Accepted 14 April 2021

\section{Check for updates}

(c) Author(s) (or their employer(s)) 2021. Re-use permitted under CC BY-NC. No commercial re-use. See rights and permissions. Published by BMJ.

For numbered affiliations see end of article.

\section{Correspondence to} Dr Rosemarie de Souza; drrosemariedesouza@gmail. com

\section{ABSTRACT}

Objective To understand the outcome of hospitalised patients from Mumbai City, which had the highest number of COVID-19 cases in India.

Design Observational study with follow-up.

Setting Data extraction from medical records of patients with COVID-19 admitted to Nair Hospital \& TN Medical College, Mumbai, India.

Participants 689 patients with COVID-19 were admitted in the hospital from 26 March 2020 to 11 May 2020.

Primary and secondary outcome measures In-hospital mortality; joint effect of comorbidity and age on the risk of dying.

Results A total of 689 patients (median age 44 years) admitted with RT-PCR-confirmed COVID-19 were included in the study. Of these, $77.36 \%$ of patients were discharged alive while $22.64 \%$ died. $11.61 \%$ required some kind of oxygen support while $2.8 \%$ of patients required intensive care unit admissions. Older age (HR 2.88, 95\% Cl 2.09 to 3.98), presence of comorbidities ( $\mathrm{HR} 2.56,95 \% \mathrm{Cl} 1.84$ to 3.55 ), history of hypertension ( $\mathrm{HR} 3.19,95 \% \mathrm{Cl} 1.67$ to 6.08), and presence of symptoms at the time of admission (HR 3.21, 95\% Cl 1.41 to 7.26 ) were associated with increased risk of in-hospital mortality. Treatment with a combination of azithromycin with hydroxychloroquine, antiviral or steroid compared with no treatment did not alter the disease course and in-hospital mortality. The combined effect of old age and presence of comorbid conditions was more pronounced in women than men. Conclusions In-hospital patients were younger, less symptomatic with lesser need of ventilators and oxygen support as compared with many western countries.

Trial registration Not applicable (observational study, not a clinical trial).

\section{INTRODUCTION}

A total of 286579 cases of RT-PCR-confirmed COVID-19 have been reported in India as of 11 June 2020, of which 8102 died due to the disease. ${ }^{1}$ Available data suggest that in India, $69 \%$ of cases are asymptomatic, while less than $15 \%$ of active cases need hospitalisation. $^{2}$ With over 30000 cases and 700 deaths, Mumbai City has the highest COVID-19 burden in the country. ${ }^{3}$ For ensuring easy

\section{Strengths and limitations of this study}

The study provides an insight into the management and course of treatment for patients with COVID-19.

- The clinical course of patients with COVID-19 admitted during the first 3 months of the outbreak in Mumbai City is described.

- The study discusses the demographical and clinical risk factors in disease outcome.

- No biomarker data were available to assess severity of COVID-19.

- This is a single-centre study and thus not representative of Mumbai City's population.

management of patients, the healthcare facilities in the city are segregated into different categories depending on symptoms and health condition of patients with COVID-19. ${ }^{4}$ These categories included COVID-19 care centres (CCCs), dedicated COVID-19 health centres (DCHCs) and dedicated COVID-19 hospitals (DCHs). ${ }^{4}$ The dedicated CCCs were meant for patients who were suspected of having COVID-19, or COVID-19-confirmed cases with mild symptoms which were cases presented with fever and/or upper respiratory tract illness (influenza-like illness). ${ }^{4}$ Cases that were clinically classified as moderate, that is, pneumonia with no signs of severe disease (respiratory rate $15-30 / \mathrm{min}, \mathrm{SpO}_{2}$ 90\%-94\%) were hospitalised in DCHCs. ${ }^{4}$ Whereas, the DCHs offered comprehensive care primarily for cases clinically classified as severe, that is, severe pneumonia (with respiratory rate $\geq 30 / \mathrm{min}$ and/or $\mathrm{SpO}_{2}<90 \%$ on room air) or acute respiratory distress syndrome or septic shock. ${ }^{4}$ Nair Hospital \& TN Medical College was the first and one of the three DCHs which started hospitalisation of COVID-19 severe cases since the beginning of the outbreak. Although the clinical characteristics and outcome of patients with COVID-19 admitted in the hospitals have 
been described in various reports from China, Italy and the USA, a detailed understanding of the clinical course of the disease for hospitalised patients from India is not known. Here we describe the clinical course of patients with COVID-19 admitted during the first 3 months of the outbreak in one of the first DCHs in the city which caters to a population dwelling in many hot spots in the city.

\section{METHODS}

\section{Study setting and participants}

The observational study was conducted at BYL Nair Charitable Hospital \& TN Medical College in Mumbai City, India. It is a 1043-bedded hospital with 110 intensive care unit (ICU) beds. In view of the hospital being designated as DCH, the bed capacities in regular wards and intensive care units were increased by $10 \%$ and $20 \%$, respectively. All diagnosed and suspected cases of COVID-19 were referred to Kasturba Hospital and Nair Hospital \& TN Medical College as they were the only DCHs in the city during the study period.

We identified 689 patients with COVID-19 admitted to these hospitals from 26 March 2020 to 11 May 2020. All patients enrolled in the study were RT-PCR positive for the SARS-CoV-2 infection. RT-PCR positivity was mandatory for diagnosis and treatment of COVID-19 at the study centre. We included patients in whom complete data were available from admission to discharge or death. The patients still admitted in the hospital at the end of the study period (as of 11 May 2020) were not included. The case files of these patients were reviewed, and information on demographical details (age, gender), comorbidities, types of comorbidities, a requirement for oxygen support, admission to ICU and details of treatment given was obtained. Treatment with azithromycin, hydroxychloroquine (HCQ), oseltamivir, lopinavir-ritonavir, steroid or oxygen support was considered to be the treatment of interest with the intention to cure. The patients who were completely asymptomatic were treated with multivitamins and zinc. For the purpose of this analysis, these patients have been considered as having received no treatment. No sample size calculations were performed. The sample size was determined by the time window of the study.

\section{Statistical analysis}

Continuous variables were summarised as mean (SD) and median (IQR). Categorised variables were summarised as count and percentages. Missing data were not included in the analysis. We estimated HRs for death, using the Cox proportional hazard model. The primary outcome was considered to be in-hospital death. We measured time to event in days from the date of hospital admission to the date of in-hospital deaths. The event was considered to be censored if individuals were discharged alive. We constructed Cox proportional HR models; one univariate and the other in which all variables were adjusted for age (continuous) and gender (categorical). From the models, HRs with $95 \%$ CI were estimated for the included variable to determine their effects on the risk of in-hospital mortality. We considered 12 variables in our Cox proportional hazard model (age, gender, comorbidities, number of comorbidities, presence of symptoms, history of hypertension alone, history of hypertension with any other comorbid conditions, history of hypertension and diabetes only, history of diabetes alone, history of diabetes with other comorbid conditions and treatment of interest).

The HR was for treatment with azithromycin only, HCQ only, azithromycin with HCQ azithromycin with steroid and azithromycin with oseltamivir compared with individuals with no treatment of interest. We adjusted these estimates for age, gender and presence of comorbidities.

We also fitted an interaction model to understand the effect of age (age less than 50 years and greater than or equal to 50 years) on gender and presence or absence of comorbidities. As the interaction was statistically significant at $5 \%$ level between age (categorical) and comorbidities, we presented a joint effect of age and comorbidities stratified by gender.

All analyses were conducted on STATA V.15.

\section{Patient and public involvement}

Patients and/or the public were not involved in the design, conduct, reporting or dissemination plans of this research. The data of enrolled patients were extracted from available case files after approval from the Institutional Ethics Committee.

\section{RESULTS}

Table 1 summarises the characteristics of patients admitted to the hospital and enrolled in the study. Patients discharged alive were much younger (median age 38, IQR 26) compared with those with in-hospital mortality (median age 55, IQR 20). A total of 351 women $(50.94 \%)$ and 338 men $(49.06 \%)$ were enrolled. Symptoms at the time of presentation were reported by $87.24 \%$ of patients who were discharged alive. Comorbid conditions were reported by 129 cases $(18.72 \%)$. No respiratory support was required for 520 patients (97.56\%) who were discharged alive, while 13 patients required some kind of respiratory support. Sixty-seven patients $(83.75 \%)$ requiring any kind of oxygen support died.

Patients' details stratified by treatment details are provided in table 2. No comorbidity or any kind of respiratory support was reported by 88 patients $(12.77 \%)$ who did not receive any COVID-19-related treatment. Comorbidities were present in $21.46 \%$ of patients who received any kind of treatment of interest. Most of the patients received azithromycin plus HCQ $(48.08 \%)$, while only azithromycin was received by $39.43 \%$ of patients. Azithromycin with oseltamivir was received by $22.79 \%$ of patients. There were three deaths in the no treatment group, while 153 out of 601 cases who received any kind of treatment of interest succumbed to the disease (table 2). 
Table 1 Basic characteristics of COVID-19-admitted patients

\begin{tabular}{|c|c|c|c|c|}
\hline \multirow[b]{2}{*}{ Variable } & \multicolumn{2}{|c|}{ Dead $(n=156)$} & \multicolumn{2}{|c|}{$\begin{array}{l}\text { Discharged alive } \\
(n=533)\end{array}$} \\
\hline & Number & $\%$ & Number & $\%$ \\
\hline \multicolumn{5}{|l|}{ Age in years } \\
\hline $10-19$ & 2 & 1.28 & 24 & 4.5 \\
\hline $20-29$ & 6 & 3.85 & 147 & 27.58 \\
\hline 30-39 & 16 & 10.26 & 109 & 20.45 \\
\hline $40-49$ & 37 & 23.72 & 74 & 13.88 \\
\hline $50-59$ & 31 & 19.87 & 101 & 18.95 \\
\hline$\geq 60$ & 64 & 41.03 & 78 & 14.63 \\
\hline Median (IQR) & $55(20)$ & & $38(26)$ & \\
\hline \multicolumn{5}{|l|}{ Sex } \\
\hline Male & 94 & 60.26 & 244 & 45.78 \\
\hline Female & 62 & 39.74 & 289 & 54.22 \\
\hline
\end{tabular}

Presence of symptoms at the time of presentation

\begin{tabular}{ccccc} 
No & 6 & 3.85 & 68 & 12.76 \\
Yes & 150 & 96.15 & 465 & 87.24 \\
\hline Comorbid conditions & & & \\
No & 98 & 62.82 & 462 & 86.68 \\
Yes & 58 & 37.18 & 71 & 13.32
\end{tabular}

Types of comorbid conditions

\begin{tabular}{|c|c|c|c|c|}
\hline Heart disease & 8 & 5.13 & 9 & 1.69 \\
\hline $\begin{array}{l}\text { Chronic } \\
\text { pulmonary } \\
\text { disease }\end{array}$ & 5 & 3.21 & 6 & 1.13 \\
\hline Diabetes & 33 & 21.15 & 34 & 6.38 \\
\hline $\begin{array}{l}\text { Kidney } \\
\text { diseases }\end{array}$ & 5 & 3.21 & 15 & 2.81 \\
\hline Liver diseases & 1 & 0.64 & 1 & 0.19 \\
\hline Hypertension & 33 & 21.15 & 33 & 6.19 \\
\hline Cancer & 5 & 3.21 & 5 & 0.94 \\
\hline
\end{tabular}

Number of comorbid conditions

\begin{tabular}{lllll|}
0 & 98 & 62.82 & 462 & 86.68 \\
1 & 30 & 19.23 & 41 & 7.69 \\
2 & 20 & 12.82 & 22 & 4.13 \\
3 & 8 & 5.13 & 7 & 1.31 \\
4 & 0 & 0.00 & 1 & 0.19
\end{tabular}

Severe acute respiratory infection*

\begin{tabular}{|c|c|c|c|c|}
\hline No & 94 & 60.26 & 419 & 78.61 \\
\hline Yes & 62 & 39.74 & 114 & 21.39 \\
\hline \multicolumn{5}{|c|}{ Was patient in ICU $(\mathrm{y} / \mathrm{n})$} \\
\hline No & 149 & 95.51 & 521 & 97.75 \\
\hline Yes & 7 & 4.49 & 12 & 2.25 \\
\hline \multicolumn{5}{|c|}{ Respiratory support } \\
\hline $\begin{array}{l}\text { No re } \\
\text { supp }\end{array}$ & 89 & 57.05 & 520 & 97.56 \\
\hline
\end{tabular}

Continued
Table 1 Continued

\begin{tabular}{clllll}
\hline & \multicolumn{2}{c}{ Dead $(\mathbf{n = 1 5 6 )}$} & & \multicolumn{2}{c}{$\begin{array}{l}\text { Discharged alive } \\
(\mathbf{n = 5 3 3})\end{array}$} \\
\cline { 2 - 3 } Variable & Number & $\%$ & & Number & $\%$ \\
\hline $\begin{array}{l}\text { Oxygen by } \\
\text { mask/cannula }\end{array}$ & 61 & 39.10 & 12 & 2.25 \\
$\begin{array}{l}\text { Non-invasive } \\
\text { ventilation }\end{array}$ & 4 & 2.56 & 1 & 0.19 \\
$\begin{array}{l}\text { Ventilator } \\
\text { support }\end{array}$ & 2 & 1.28 & 0 & 0.00 \\
$\begin{array}{l}\text { Median (IQR) } \\
\text { length of stay in } \\
\text { hospital }\end{array}$ & $1(3)$ & & & & \\
\hline
\end{tabular}

${ }^{*}$ Respiratory rate $>30$ breaths/min, severe respiratory distress, $\mathrm{SpO}_{2}<90 \%$ on room air. $\mathrm{ICU}$, intensive care unit.

Age, gender (male) and history of any comorbidities were associated with an increased risk of dying. Having a history of hypertension was independently associated with more than twofold risk of dying. There was no change in the disease course in patients who received any treatment (single-agent azithromycin or in combination with HCQ, oseltamivir or steroids) as compared with the no treatment group (table 3 and online supplemental table 1 ).

The joint effect of older age and comorbidity stratified by gender is presented in figure 1 . The HR of dying for a woman with the comorbid condition and older age was observed to be 8.10 (95\% CI 4.04 to 16.23), while that for men with the comorbid condition and older age was observed to be 2.87 (95\% CI 1.63 to 5.05 ).

\section{DISCUSSIONS}

The present study describes the clinical course of the patients admitted in a major COVID-19 care hospital of Mumbai City during the first 2 months of the epidemic. Initially, in the first 2 months, only Kasturba Hospital and Nair Hospital \& TN Medical College were designated as $\mathrm{DCH}$ and were working in collaboration for treating the patients. The enrolled study participants in the study, therefore, provide a representative sample of patients with COVID-19 admitted in hospital (DCH facility). The study, however, did not include the mildly symptomatic or asymptomatic COVID-19-affected patients, as this group of patients was admitted in DCHC.

The data suggest that admitted patients with COVID-19 are younger (median age 44 years) compared with that reported by the US and European population (median age 62 years $)^{5}$; with less proportion of comorbid conditions $(18.72 \%)$ compared with western countries $(14.40 \%-60.10 \%){ }^{6}$ Further, a history of hypertension and diabetes was reported only by $9.58 \%$ and $9.72 \%$ of enrolled individuals.

The patients coming to DCH were severely symptomatic, whereas mildly symptomatic and asymptomatic patients 


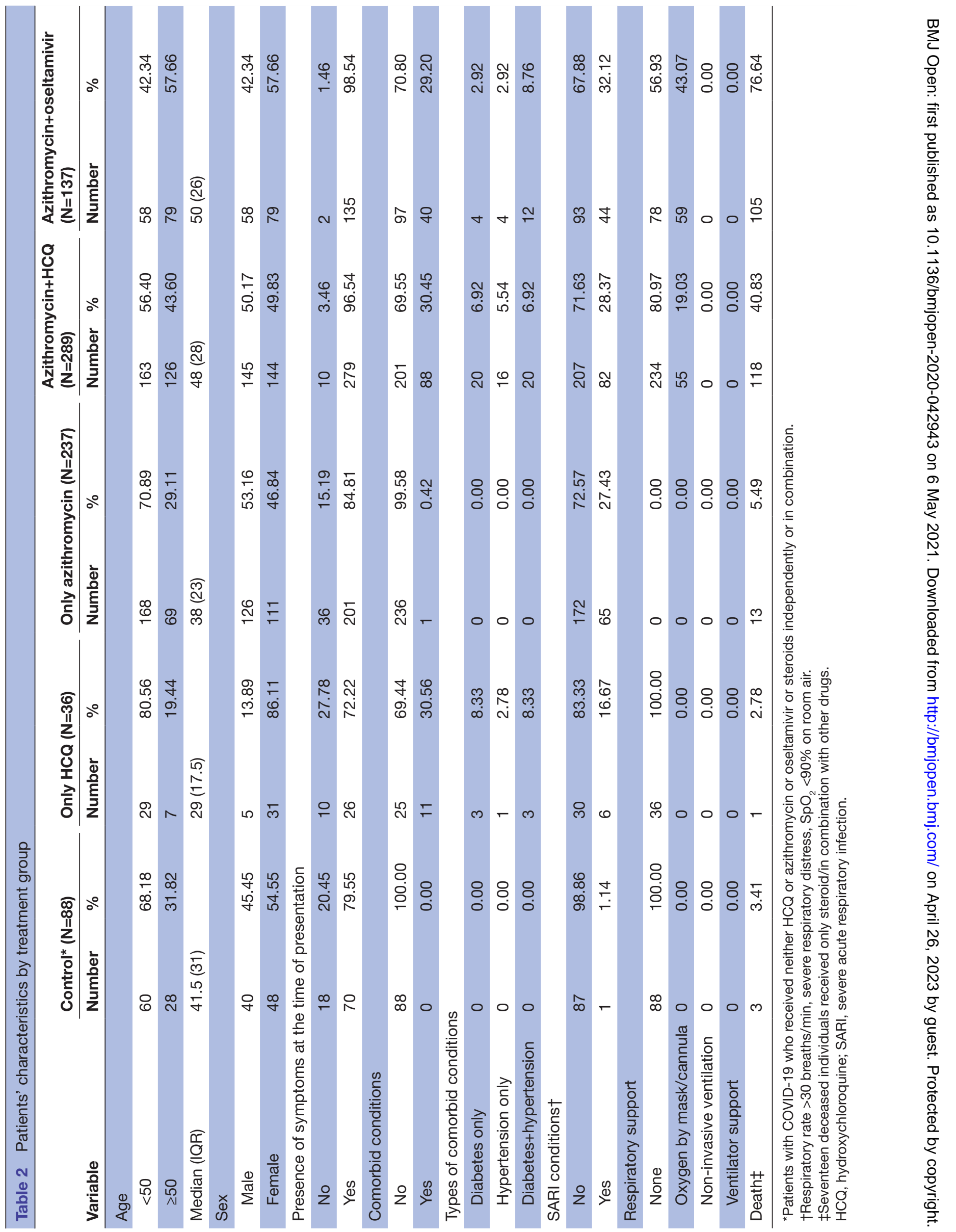


Table 3 Risk factors for in-hospital mortality from patients with COVID-19

\begin{tabular}{|c|c|c|c|}
\hline Variable & Dead|alive & HR $(95 \% \mathrm{Cl})^{*}$ & P value* \\
\hline Age (per year increase) & & 1.03 (1.02 to 1.04$)$ & $\leq 0.0001$ \\
\hline$<50$ & $63 \mid 376$ & Reference & \\
\hline \multicolumn{4}{|l|}{ Gender } \\
\hline Female & $62 \mid 289$ & Reference & \\
\hline \multicolumn{4}{|l|}{ Comorbidities } \\
\hline No & $98 \mid 462$ & Reference & \\
\hline Yes & $58 \mid 71$ & 2.56 (1.84 to 3.55$)$ & $\leq 0.0001$ \\
\hline \multicolumn{4}{|c|}{ Number of comorbid conditions } \\
\hline 0 & $98 \mid 462$ & Reference & \\
\hline
\end{tabular}

Types of comorbid conditions:

Hypertension only

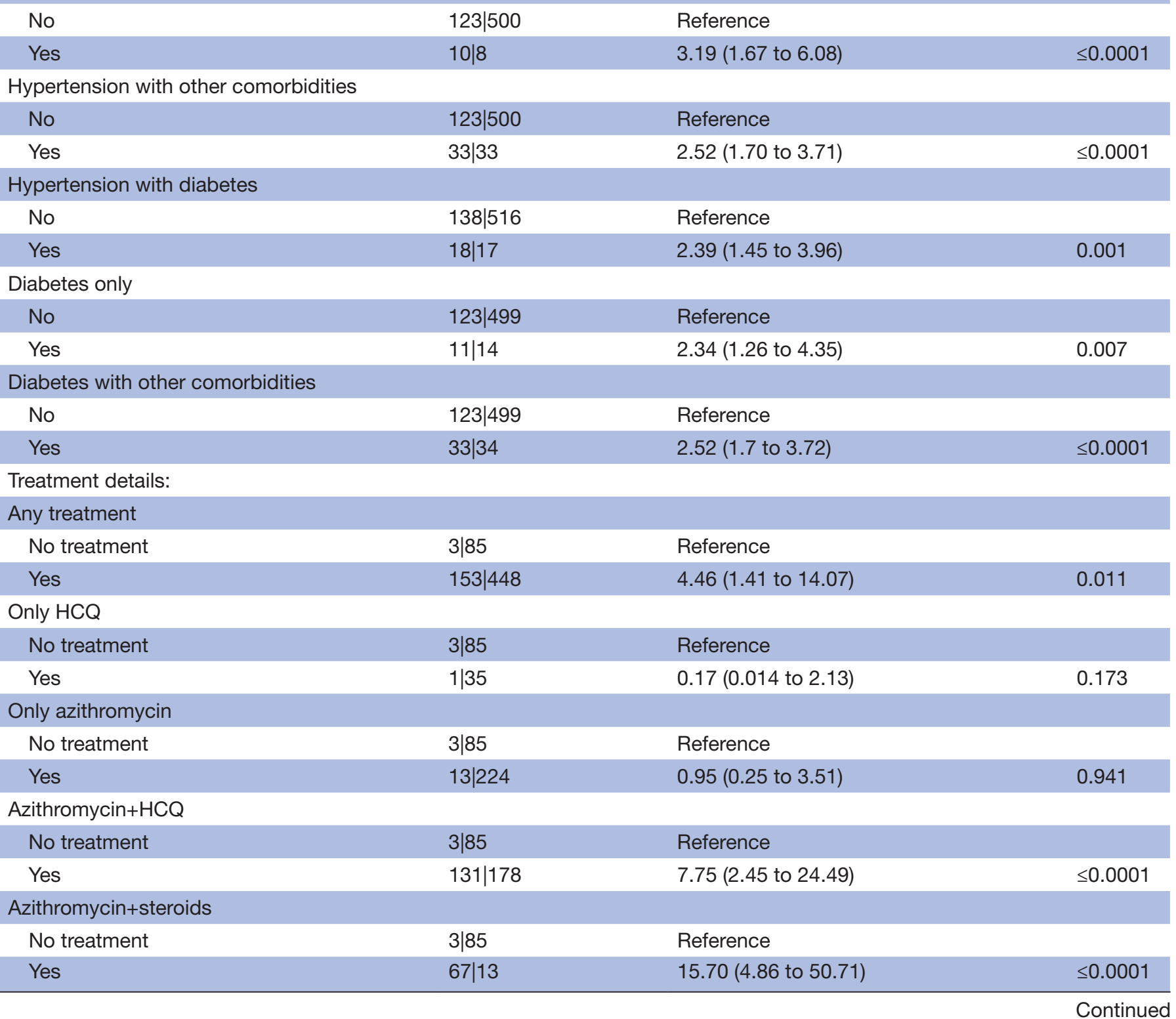


Table 3 Continued

\begin{tabular}{|c|c|c|c|}
\hline Variable & Dead|alive & HR $(95 \% \mathrm{Cl})^{*}$ & P value* \\
\hline No treatment & $3 \mid 85$ & Reference & \\
\hline \multicolumn{4}{|c|}{ Azithromycin+oseltamivir } \\
\hline No treatment & $3 \mid 85$ & Reference & \\
\hline \multicolumn{4}{|c|}{ Symptoms at the time of presentation } \\
\hline No & $6 \mid 68$ & Reference & \\
\hline Yes & $150 \mid 465$ & 3.21 (1.41 to 7.26$)$ & 0.005 \\
\hline \multicolumn{4}{|c|}{ Severe acute respiratory infection } \\
\hline No & $89 \mid 520$ & Reference & \\
\hline Yes & $67 \mid 13$ & 5.70 (4.14 to 7.84$)$ & $\leq 0.0001$ \\
\hline
\end{tabular}

${ }^{*} \mathrm{HR}$ calculated using univariate analysis.

$\mathrm{HCQ}$, hydroxychloroquine.

were referred to DCHC. The death rate in our series was therefore higher as cases admitted to the hospital were late in their disease course and thus possibly only severely sick patients were hospitalised leading to high in-hospital mortality.

The current study also highlights that the number of admitted patients requiring oxygen support is very low (11.61\%); only a small proportion requires ICU admissions $(2.76 \%)$ and ventilation support $(0.29 \%) .{ }^{67}$ This is comparable with data from India with a requirement of oxygen support reported to be $1.91 \%$ with $2.25 \%$ requiring ICU care and only $0.0004 \%$ with the need for a mechanical ventilator. ${ }^{8}$ Many western countries and the USA have reported higher requirement of admission to ICU $(1 \%-26 \%)$, ventilation support $(3 \%-88 \%)$ and requirement of any kind of oxygen support $(1 \%-55 \%))^{6-13}$

The lower requirement of ICU and oxygen support in admitted patients in India has a huge implication for developing strategies for healthcare of patients with COVID-19. Given the high density of population in residential areas, the strategy in India and particularly in Mumbai should focus on spacious areas and facilities to quarantine positive cases. There seems to be a much lesser need for ventilators and ICU for treating patients with COVID-19 in India compared with western countries.

A total of 156 deaths were observed in admitted patients. The risk of death was higher for older patients (age greater than 50 years) and among men. Hypertension was observed to be one of the strongest risk factors for mortality. This is consistent with data from in-hospital mortality reported from New York City, China and Italy. ${ }^{6-16}$ Given the globally high burden of hypertension and a possible understanding of the interaction between SARS-CoV-2 and ACE-2, it will be important to obtain information related to drugs (beta-blockers or ACE-2 inhibitors) taken by patients with hypertension. ${ }^{17}$ We observed statistical significant multiplicative interaction between old age and comorbidity. The joint effect of older age and the presence of comorbid conditions on the risk of dying was higher among women (HR 8.10, $95 \%$ CI 4.04 to 16.23 ) than among men (HR 2.87, 95\% CI 1.63 to 5.05$)$.

We evaluated the effect of azithromycin alone, HCQ alone and the combination of azithromycin with HCQ, oseltamivir and steroid on the risk of dying. All these drugs were administered with an intention to cure and were supposed to be effective against SARS-CoV-2. However, we observed no change in the disease course with all of these treatments of interest when compared with a group of individuals who did not receive any treatment. These results should be interpreted with caution as none of the no treatment group of patients had any comorbidity or required any oxygen support. As no treatment group was asymptomatic or mildly symptomatic, only three of them died; while almost all of them were discharged with advice to quarantine. Thus, the treatment of interest was given to a more symptomatic group of patients which could be responsible for high risk of death we observed with any of the treatment of interest. We therefore cannot conclude that these treatment combinations increase risk of death. However, our results suggest that these repurpose drugs could not alter the clinical course of the disease among this group. The same has been concluded in many randomised clinical trials which showed no reduction in mortality from these drugs. ${ }^{18-20}$ 

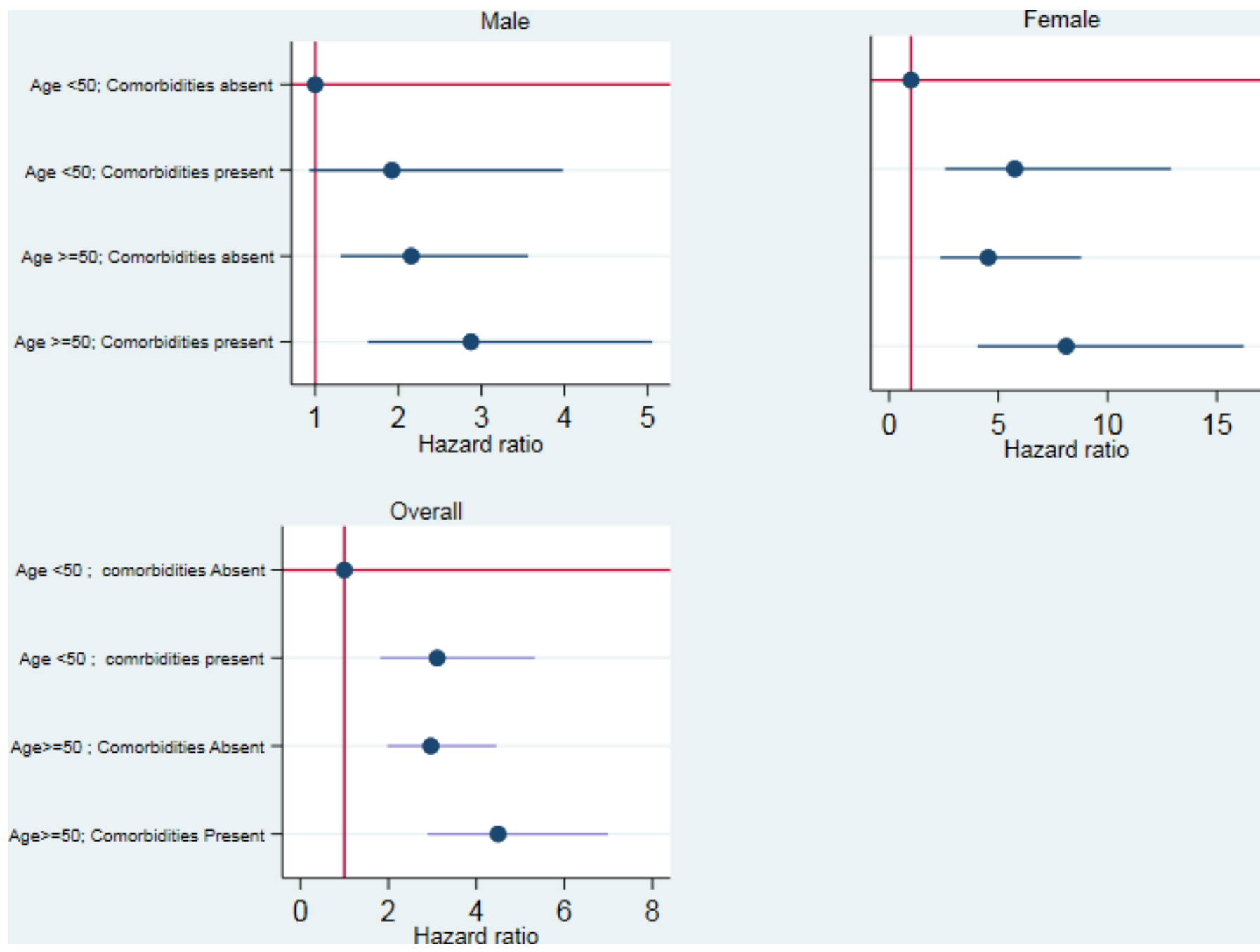

Figure 1 Hazard of death in association with comorbidities and age.

Our study does not have biomarker data to assess the severity of disease and does not capture possible heterogeneity which might be there among patients with COVID-19 from different parts of India. There might be also differences in the socioeconomic strata of the patients admitted to centres other than TN Medical College \& BYL Nair Hospital. A planned study will be required in understanding the difference in socioeconomic status associated with the development and progression of COVID-19 infection.

Our study provides reports of the clinical course of patients with COVID-19, admitted during the first 2 months of an epidemic in a city with the highest number of cases. The study confirms that patients with COVID-19 in India are younger in age, have less number of comorbid conditions and possibly have a lesser need for intensive care.

\footnotetext{
Author affiliations

${ }^{1}$ Department of Medicine, BYL Nair Charitable Hospital, Mumbai, India

${ }^{2}$ Centre for Cancer Epidemiology, Tata Memorial Centre, Navi Mumbai, India

${ }^{3} \mathrm{Head}$ and Neck Services, Tata Memorial Hospital, Mumbai, India

${ }^{4}$ Department of Breast Oncology, Tata Memorial Hospital, Mumbai, India

${ }^{5}$ Medical Oncology, Tata Memorial Centre, Mumbai, India
}

${ }^{6}$ Medical Oncology, Homi Bhabha National Institute, Mumbai, India ${ }^{7}$ Centre for Cancer Epidemiology, Tata Memorial Centre, Mumbai, India ${ }^{8}$ Surgical Oncology, Tata Memorial Centre, Mumbai, India

Acknowledgements The authors acknowledge with thanks the contribution of $\mathrm{Dr}$ Christopher de Souza for editing the English language.

Contributors RdS, PC, SG, RD, RB, GC and SM were involved in the conceptualisation of the study, RdS, BQ, PL and TM were involved in the acquisition of the data and conduct of the study. SM performed the statistical analysis. RdS, PC $\mathrm{SG}, \mathrm{RD}, \mathrm{RB}, \mathrm{GC}, \mathrm{SM}, \mathrm{MJ}$ and DSA were involved in the interpretation of the data. All authors contributed to drafting this manuscript, with RdS taking a lead role; she is also the guarantor of the manuscript. All authors gave intellectual input to improve the manuscript, and have read and approved the final version.

Funding Tata Memorial Centre, Mumbai.

Competing interests None declared.

Patient consent for publication Not required

Ethics approval The study was approved by the Institutional Ethics Committee (IEC) of Nair Hospital \& TN Medical College, Mumbai. IEC agreed to our request for waiver off of individual consent as no direct communication/contact with cases was involved and all data were extracted from medical case records.

Provenance and peer review Not commissioned; externally peer reviewed. Data availability statement Data are available upon reasonable request.

Supplemental material This content has been supplied by the author(s). It has not been vetted by BMJ Publishing Group Limited (BMJ) and may not have been 
peer-reviewed. Any opinions or recommendations discussed are solely those of the author(s) and are not endorsed by BMJ. BMJ disclaims all liability and responsibility arising from any reliance placed on the content. Where the content includes any translated material, BMJ does not warrant the accuracy and reliability of the translations (including but not limited to local regulations, clinical guidelines, terminology, drug names and drug dosages), and is not responsible for any error and/or omissions arising from translation and adaptation or otherwise.

Open access This is an open access article distributed in accordance with the Creative Commons Attribution Non Commercial (CC BY-NC 4.0) license, which permits others to distribute, remix, adapt, build upon this work non-commercially, and license their derivative works on different terms, provided the original work is properly cited, appropriate credit is given, any changes made indicated, and the use is non-commercial. See: http://creativecommons.org/licenses/by-nc/4.0/.

\section{ORCID iDs}

Sudeep Gupta http://orcid.org/0000-0002-6742-6378

Rajesh Dikshit http://orcid.org/0000-0003-4830-0486

\section{REFERENCES}

1 MoHFW. MoHFW | home, 2020. Available: https://www.mohfw.gov. in/index.htm

2 The Times of India. ICMR | India News - Times of India, 2020. Available: https://timesofindia.indiatimes.com/india/69-of-casesfound-positive-were-asymptomatic-icmr/articleshow/75282825.cms

3 COVID-19 INDIA. Coronavirus in India: latest map and case count, 2020. Available: https://www.covid19india.org

4 MoHFW. MoHFW | home, 2020. Available: https://www.mohfw.gov. in/pdf/FinalGuidanceonMangaementofCovidcasesversion2.pdf

5 Cummings MJ, Baldwin MR, Abrams D, et al. Epidemiology, clinical course, and outcomes of critically ill adults with COVID-19 in New York City: a prospective cohort study. The Lancet 2020;395:1763-70.

6 Richardson S, Hirsch JS, Narasimhan M, et al. Presenting characteristics, comorbidities, and outcomes among 5700 patients hospitalized with COVID-19 in the new York City area. JAMA 2020;323:2052-9.

7 Myers LC, Parodi SM, Escobar GJ, et al. Characteristics of hospitalized adults with COVID-19 in an integrated health care system in California. JAMA 2020;323:2195-8.
8 The State. The state, 2020. Available: https://thestateindia.com/ 2020/06/09/after-america-its-india-with-most-serious-patients-ofcorona-virus

9 Goyal P, Choi JJ, Pinheiro LC, et al. Clinical characteristics of Covid-19 in New York City. N Engl J Med Overseas Ed 2020;382:2372-4.

10 Argenziano MG, Bruce SL, Slater CL, et al. Characterization and clinical course of 1000 patients with coronavirus disease 2019 in New York: retrospective case series. BMJ 2020;369:m1996.

11 Shekerdemian LS, Mahmood NR, Wolfe KK, et al. Characteristics and outcomes of children with coronavirus disease 2019 (COVID-19) infection admitted to US and Canadian pediatric intensive care units. JAMA Pediatr 2020;174:868.

12 Grasselli G, Zangrillo A, Zanella A, et al. Baseline characteristics and outcomes of 1591 patients infected with SARS-CoV-2 admitted to ICUs of the Lombardy region, Italy. JAMA 2020;323:1574-81.

13 Guan W-jie, Liang W-hua, Zhao Y, Guan W, Liang W, et al. Comorbidity and its impact on 1590 patients with COVID-19 in China: a nationwide analysis. European Respiratory Journal 2020;55:2000547.

14 Huang R, Zhu L, Xue L, et al. Clinical findings of patients with coronavirus disease 2019 in Jiangsu province, China: A retrospective, multi-center study. PLoS Negl Trop Dis 2020;14:e0008280

15 Zhou F, Yu T, Du R, et al. Clinical course and risk factors for mortality of adult inpatients with COVID-19 in Wuhan, China: a retrospective cohort study. The Lancet 2020;395:1054-62.

16 Kreutz R, Algharably EAE-H, Azizi M, et al. Hypertension, the renin-angiotensin system, and the risk of lower respiratory tract infections and lung injury: implications for COVID-19. Cardiovasc Res 2020;116:1688-99.

17 Mali SN, Thorat BR, Chopade AR. A viewpoint on angiotensinconverting enzyme 2, Anti-Hypertensives and coronavirus disease 2019 (COVID-19). Infect Disord Drug Targets 2020;20.

18 Tang W, Cao Z, Han M, et al. Hydroxychloroquine in patients with mainly mild to moderate coronavirus disease 2019: open label, randomised controlled trial. BMJ 2020 14;369:m1849.

19 Cao B, Wang Y, Wen D, et al. A trial of Lopinavir-Ritonavir in adults hospitalized with severe Covid-19. New England Journal of Medicine 2020;382:1787-99.

20 van Paassen J, Vos JS, Hoekstra EM. Corticosteroid use in COVID-19 patients: a systematic review and meta-analysis on clinical outcomes. Crit Care 2020;14;24:696. 